\title{
Las relaciones México-Estados Unidos, 1756-2010. Cuatro áreas estratégicas
}

\author{
Sergio M. Alcocer Martínez de Castro*
}

No hay ninguna otra relación en el ámbito de la política exterior más importante para México que la que tenemos con Estados Unidos. Esto es cierto, tanto por su diversidad y profundidad de los temas, como por su inherente complejidad. Empero, tal fascinante relación debe ser analizada en el decurso del tiempo desde sus múltiples dimensiones. Por ello, el libro Las relaciones México-Estados Unidos, 1756-2010 resulta tan relevante. De hecho, estoy seguro de que esta obra se convertirá en una referencia obligada, en un libro de texto, para quienes buscan entender los retos y oportunidades que plantea la relación entre estos dos países.

Una de las premisas que debe llevar a los estudiosos y curiosos a la consulta de los dos volúmenes del libro es que es necesario conocer bien el pasado, aprender sus lecciones, comprender sus detalles $\mathrm{y}$, justamente, no anclarse en éstos. Recordemos: la historia se asume. A partir de esta comprensión, hoy podemos y debemos repensar la relación entre México y Estados Unidos con la finalidad de hacerla madurar y que sea más fructífera para ambas sociedades.

El desafío no es menor, ya que hay que superar los obstáculos que imponen las diferencias culturales y también hay que dejar atrás las desconfianzas mutuas, los prejuicios y los estereotipos. No es casual que en su visita a México, durante mayo de 2013, el presidente Obama haya dedicado buena parte de su discurso en el Museo de Antropología a reconocer que esas diferencias existen. Él y el presidente Peña Nieto fueron asimismo claros en subrayar las grandes oportunidades que la relación ofrece si ambos países se concentran en sus muchas coincidencias, en sus intereses

\footnotetext{
* Subsecretario para América del Norte, Secretaría de Relaciones Exteriores, SAlcocerM@ iingen.unam.mx. Reseña basada en el discurso pronunciado por el autor durante la presentación del libro en la sede de la Secretaría de Relaciones Exteriores.
} 
y necesidades mutuas. Lo que nos ofrece este libro es, precisamente, la oportunidad de entender las raíces de esas coincidencias y necesidades.

Hay cuatro puntos cardinales, cuatro áreas estratégicas que esta obra nos presenta a manera de carta de navegación. A continuación las comento.

La primera se refiere a la interacción económica entre ambos países. Como se relata en el libro, desde finales de la década de los setenta del siglo XIX, en México ganó fuerza la visión de que las relaciones económicas con Estados Unidos son ventajosas (Terrazas y Basante y Gurza Lavalle, 2013, vol. I: 76 y 77). Así, el énfasis en la relación pasó de la necesidad de

Los pueblos se desplazan a los lugares donde existen las oportunidades y los productos. protegerse frente a la amenaza estadunidense, a reconocer las ventajas que ésta presentaba para nuestro desarrollo económico. En efecto, los pueblos se desplazan a los lugares donde existen las oportunidades y los productos. Sin embargo, no fue sino hasta la firma del Tratado de Libre Comercio para América del Norte (TLCAN) que el destino de las economías de ambas naciones quedó indisolublemente vinculado. Es decir, como los autores señalan, "la profundización de la integración económica y el arrastre que ejerce la economía estadunidense tienen como consecuencia la sincronización de los ciclos económicos de México y Estados Unidos" (Riguzzi y De los Ríos, 2013, vol. II: 545).

Esto, desde luego, tiene una parte negativa, pues, como lo demostró una vez más la crisis iniciada en 2008, la recesión de la economía estadunidense impacta duramente a la economía mexicana. Por ello se ha señalado la importancia de diversificar el comercio exterior de México. Pero si esto es una medida prudente y necesaria, también es cierto que la relación comercial con Estados Unidos sigue -y seguirá siendo- el vínculo económico más importante de nuestro país durante muchos años.

Geografía es destino y nuestro país tiene una posición privilegiada, dado que estamos al lado del que sigue siendo el mayor mercado de consumidores del mundo. Estados Unidos es, además, el eje del intercambio comercial en todo el continente. Y aquí es donde están las oportunidades para repensar nuestra relación, con una visión estratégica y global que proyecte a América del Norte como región y no como países aislados, como un nuevo enclave de productividad, innovación y competitividad a escala internacional.

La agenda estratégica que impulsa la Cancillería con nuestros pares estadunidenses establece claramente que tenemos que redoblar nuestra apuesta por los intercambios educativos y científicos, pues sólo a partir 
del conocimiento podremos competir en igualdad de circunstancias con zonas de mayor dinamismo económico. Además, es el conocimiento -es decir, la educación- el mejor medio de inclusión social. Estoy convencido de que son los jóvenes de ambos países quienes, a través de un mejor conocimiento de sus pares de la otra nación, podrán convertir las oportunidades de la relación en bienestar. Con este fin se creó el Foro Bilateral sobre Educación Superior, Innovación e Investigación.

La segunda área de oportunidad para repensar la relación entre México y Estados Unidos está en la migración. Como se señala en este libro, en los debates identitarios estadunidenses siempre han existido grupos que proyectan a los inmigrantes como "fuente de todos los males" (Riguzzi y De los Ríos, 2013, vol. II: 565). Actualmente, el estereotipo sobre migración en Estados Unidos sigue sujeto a un pasado que ya fue: uno en el que miles y miles de mexicanos pobres cruzaban la frontera desesperados para ocupar trabajos estadunidenses.

La realidad es que los cambios demográficos en México, sumados al desarrollo de nuestro país, apuntan a una nueva realidad. La tasa de migración a Estados Unidos cada año es más baja. Sumemos a esto el envejecimiento de la población estadunidense que está trayendo cambios fundamentales en su estructura productiva. No es descabellado imaginar un futuro cercano en el que Estados Unidos sea la parte que busque activamente un acuerdo migratorio bilateral para asegurarse la provisión de los miles de trabajadores que permitan mantener su enorme economía funcionando. Con visión de largo plazo, tenemos que empezar a preparar a nuestras sociedades para ese escenario desde hoy. Debemos de imprimir a esta agenda un sentido humano, reconociendo al migrante, a las comunidades mexicanas en el exterior, como sujetos de derechos y actores del desarrollo de sus comunidades de origen y destino. De ahí que la Cancillería despliegue esfuerzos permanentes de protección consular y de empoderamiento de la población mexicana.

La tercera área de oportunidad está en la frontera entre México y Estados Unidos. Como lo exponen los autores de esta obra, la guerra de 1847 dibujó una franja entre nuestras naciones que, en años recientes, muchos han tratado de convertir, absurdamente, en un muro infranqueable. No obstante, la historia nos demuestra que, por más murallas que se construyan, la gente es quien realmente determina dónde se trazan las fronteras. En este sentido, nuestra frontera con Estados Unidos es más diversa, flexible y porosa de lo que los mapas y los miopes admiten.
La historia nos demuestra que, por más murallas que se construyan, la gente es quien realmente determina dónde se trazan las fronteras. 
Como se señala en el segundo volumen, "la frontera México-Estados Unidos es una región que incluye diversas fronteras, no sólo por el cambio de sus límites a lo largo de la historia, sino por la dinámica entre los diferentes estados y municipios o condados de ambos lados" (Riguzzi y De los Ríos, 2013, vol. II: 392). Se trata de un espacio dinámico, en el que se realizan intercambios de todo tipo que marcan la identidad de las sociedades que ahí habitan. Esto ha detonado el desarrollo de ciudades gemelas, como El Paso-Ciudad Juárez y Tijuana-San Diego, que se comportan como una sola metrópoli transfronteriza. Pero, debido a esto, tenemos que generar un nuevo modelo de ciudades globales sustentables que responda a la necesidad de crecimiento y desarrollo, con calidad de vida.

En sociedades tan estrechamente vinculadas, los desafíos y oportunidades a la prosperidad son necesariamente compartidos.
Las interacciones sociales, económicas y culturales son una posibilidad única para consolidar un espacio común que sea motor de desarrollo y no de conflicto. Los flujos de bienes y personas en la frontera han demostrado ser una fuente de prosperidad para la región norteamericana. Hay que construir sobre esta experiencia y encontrar esquemas de cooperación binacional que impulsen el desarrollo a ambos lados de la frontera. Hoy tenemos la responsabilidad de reconocer que, en sociedades tan estrechamente vinculadas, los desafíos y oportunidades a la prosperidad son necesariamente compartidos. Más puentes y menos muros es lo que se debe construir.

La última área a la que me quiero referir es a las percepciones culturales. Como lo explican con claridad los autores, los estereotipos construidos en cada país sobre su vecino han sido un obstáculo para el desarrollo de una relación bilateral próspera. Esto incluso ha llegado a contaminar la visión de historiadores mexicanos que han estudiado la relación entre México y Estados Unidos. Como menciona Alan Knight en la presentación del libro: "las historias más viejas tendían a adoptar tonos nacionalistas y resentidos [...] Estados Unidos era un ogro amenazador, protestante y depredador y, como un ogro es un ogro, no era necesario hacer un análisis sensible y sagaz de la política y los motivos estadunidenses" (Terrazas y Basante y Gurza Lavalle, 2013, vol. I: 14).

Precisamente, en este punto radica una de las virtudes de la obra que se reseña. Haciendo a un lado los viejos arquetipos, los autores logran un análisis balanceado de las relaciones políticas, económicas, sociales y culturales que se han desarrollado a lo largo de la historia entre México y Estados Unidos. Sin duda, esto representa un ejemplo a seguir no sólo para la elaboración futura de estudios sobre el tema, sino también 
para el diseño e implantación, todos los días, de la política exterior. En efecto, en el caso de México, se trata de usar el poder suave, es decir, la persuasión y la diplomacia cultural, para negociar y convencer.

Debemos dejar atrás prejuicios históricos que nublan la vista en ambos lados de la relación. Desde hace varias décadas, México y Estados Unidos dejaron de ser competidores para convertirse en aliados del progreso mutuo. Tenemos que convencernos de ello, ellos y nosotros. También tenemos que abandonar el reduccionismo economicista que explica la relación entre nuestros países como un mero trámite comercial. Por lo tanto, estudios como éste son tan necesarios, porque retan visiones simplistas y erróneas que anulan los beneficios de la vecindad y la asociación. Son textos que destacan el conjunto, denso, estratificado y amplio que son nuestras relaciones. Permite reconocer que la relación México-Estados Unidos gira alrededor de migrantes, turistas, artistas, científicos, trabajadores y empresarios.

En la parte estadunidense, se requiere acabar con estereotipos que presentan a México como el vecino problemático y, en su lugar, otorgar el peso justo a las contribuciones que nuestro país hace al desarrollo de Estados Unidos. En la parte mexicana, es tiempo de dejar atrás visiones que presentan a Estados Unidos como el vecino oportunista que usa y abusa de su poder para sacar el mayor provecho de la relación con México. Como este libro deja en claro, históricamente, han existido muchos espacios en los que ha predominado la cooperación sobre la imposición.

La asimetría de poder no es lo que determina hoy la relación entre México y Estados Unidos. Nuestro pasado, presente y futuro seguirán estrechamente vinculados. Por ello, es tiempo de aceptar que la geografía y la historia nos continuarán orillando a caminar de la mano. $\mathrm{O}$, como lo señaló el presidente Obama: México y Estados Unidos son “dos socios iguales, dos naciones soberanas que deben trabajar juntas con interés y respeto mutuos".

La historia no puede cambiarse; pero el futuro sí. ¿Cómo queremos que sea ese futuro? Es la gran pregunta. En este sentido, México debe trabajar para que ese futuro sea de mayor cooperación, amplia y profunda, así como que exista mejor comprensión con nuestros vecinos estadunidenses en beneficio de nuestras sociedades. México debe asumir el liderazgo de una visión regional moderna que se sustente en una mayor competitividad, calidad de vida, sustentabilidad, a la par que en la innovación y el conocimiento. Eso explica el énfasis en la educación, la ciencia, la tecno-
La asimetría de poder no es lo que determina hoy la relación entre México y Estados Unidos. 
logía, la infraestructura, la energía, las comunicaciones, entre otras, en la agenda actual entre los gobiernos de México y Estados Unidos.

\section{BibliografíA}

\section{Analizada}

Terrazas y Basante, Marcela, Gerardo Gurza Lavalle, eds.

Riguzzi, Paolo y Patricia de los Ríos, eds.

2013 Las relaciones México-Estados Unidos, 1756-2010, vol. I: Imperios, repúblicas y pueblos en pugna por el territorio, 1756-1867/vol. II: ¿Destino manifiesto?, 1867-2010, México, IIH-CISAN, UNAM/SRE.

\section{Consultada}

Passel, Jefrrey S., D’Vera Cohn y Ana Gonzalez-Barrera

2012 "Net Migration from Mexico Falls to Zero-and Perhaps Less", Pew Research, Hispanic Trends Project, en <http: / / www.pewhispanic.org/2012/04/23/net-migration-from-mexico-falls-to-zero-and-perhaps-less $/>$. 